\title{
Using health psychology to help patients: promoting wellbeing
}

\section{Elizabeth Barley and Victoria Lawson BJN 2016}

This article explores the construct of wellbeing. Research concerning the relationship between subjective wellbeing and health is discussed. Key components of wellbeing which are important to health include 'sense of coherence', 'optimism' and 'benefit-finding and posttraumatic growth'. A range of positive psychology interventions which aim to increase positive thoughts, feelings and emotions in order to improve wellbeing has been developed. Mindfulness based approaches to improving wellbeing are especially popular and are evidence based. These focus on helping the individual to develop an awareness of the present with acceptance and attention. Instead of trying to change uncomfortable thoughts or feelings, the individual practices accepting these, without judgement. Nurses can draw on the information in this article to provide evidence-based advice and guidance to help improve their patients' and their own wellbeing.

Better wellbeing is associated with living longer (Steptoe et al, 2015). There is also a relationship between physical health and wellbeing: poor health reduces wellbeing and high wellbeing reduces impairments due to physical health problems (Steptoe et al, 2015). Attention to patients' wellbeing is therefore an essential aspect of providing holistic care. Components of wellbeing that can be measured objectively include factors important to functioning and quality of life such as income level, material conditions and job security. However, the person's perception of how they are doing - their internal 'subjective wellbeing' can be more important than their literal, objective wellbeing as might be assessed externally. This article considers the research on the impact of subjective wellbeing (henceforth termed 'wellbeing') on health and functioning and on interventions which may improve wellbeing.

There is no universally agreed definition of 'wellbeing'. Within the research literature several related constructs have either been treated as synonymous with wellbeing or as a component of it, for instance 'happiness', 'positive affect', 'life satisfaction' and 'quality of life' (Dodge et al, 2012, Diener and Suh, 1997). It is agreed however that wellbeing is a multi-dimensional construct. Recently three dimensions have been proposed to encompass all components of wellbeing in relation to aging: 1) life evaluation, 2) hedonic wellbeing, and 3) eudaimonic wellbeing (Steptoe et al, 2015).

'Life evaluation' is people's perception the overall quality or 'goodness' of their lives and so encompasses life satisfaction and quality of life.

The concept of 'hedonic wellbeing' derives from a philosophic perspective which suggests that happiness involves maximising one's pleasurable moments (Henderson and Knight, 2012). However, to measure 'hedonic wellbeing' both positive and negative feelings should be measured. This is because positive emotions, such as happiness, and negative emotions, such as sadness or anger, are not entirely inversely related. These emotions can co-occur, for example simultaneously feeling happy to be appointed to a new job and anxious about what it might entail.

The construct 'eudaimonic wellbeing' derives from Aristotle's idea of 'eudaimonia' and the philosophical idea that the way to wellbeing is to live a virtuous life and to achieve one's full 
potential (Henderson and Knight, 2012). Eudomonic wellbeing therefore reflects an individual's judgment about the meaning and purpose of their life.

However, even these dimensions are broad and hence difficult to operationalise for research purposes, consisting as they do of complex, interrelated subjective components. Therefore research on the association between wellbeing, health and functioning has focused on more specific components of wellbeing that are comparatively simpler to measure objectively. The three of the most commonly studied being 'sense of coherence', 'optimism' and 'benefitfinding and posttraumatic growth’ (Aspinwall and Tedeschi, 2010).

\section{Relationship between Wellbeing and Health}

'Sense of coherence' is used to refer to 'an individual's global view of life, based on how comprehensible, manageable and meaningful life appears to them' (Rohani et al, 2010). An adverse event, such as illness, is proposed to be less stressful if the person experiencing it can understand it and feels that they have what they need to cope with it (Antonovsky, 1987). Having a sense of meaning is thought to be the motivation for trying to understand and cope (Aspinwall and Tedeschi, 2010). A sense of coherence is beneficial to health, especially mental health; a review of nearly 500 studies found that it strengthens resilience and helps develop a positive perceived health irrespective of participant age, sex, ethnicity, nationality or of study design (Eriksson and Lindstrom, 2006).

Optimism refers to generalized tendency to expect life events to go well, sometimes equated with 'hope' (Sharpe et al, 2011). There exists some dispute around the nature of optimism. Herzberg et al (2006) conceptualised optimism and pessimism as being at opposite ends of the scale, whilst optimism and pessimism have also been explored as being separate constructs (Kubzansky et al 2004). There has also been some debate about whether optimism is a dispositional trait or explanatory style (Seligman \& Csikszentmihalyi, 2000). This can make interpreting the literature difficult. For instance, a systematic review of 83 studies of the relationship between optimism and physical health found wide variation in effect sizes of between -0.13 and 0.42 (mean 0.17 ) which was considered to be due to differences in how optimism was operationalized and measured in different studies (Rasmussen et al, 2009). Optimism has also been studied as a moderator between objective and subjective physical health. In a longitudinal study of 309 older adults (aged 65-85 years) with multimorbidities, subjective ratings of physical functioning were predicted by both objective physical functioning and by optimism (Warner et al, 2012). However, optimism predicted subjective physical functioning only for those participants reporting low self-efficacy. This suggests that optimistic people may underestimate their vulnerability and simultaneously overestimate their ability to cope (Warner et al, 2012).

'Benefit finding', the ability to identify advantages in adverse circumstances, including illness, has been found to be associated with lower depression and better wellbeing (Helgeson et al, 2006). Benefit finding behaviour is not uncommon, for example, in a study where 548 participants with coronary heart disease were asked "Has having heart disease changed your life? If so, was that change for the better, worse, both or neither?" 22 per cent reported that it was better (Smith et al, 2014). Reasons given included living more healthily, appreciating their mortality and having taken measures to reduce stress. Posttraumatic growth, the experience of personal growth whilst dealing with stress and trauma, including physical illness may be linked to benefit finding (Aspinwall and Tedeschi, 2010). It is proposed that trauma prompts the individual to reappraise their view of the world. 'Growth' is evidenced by 
a greater sense of personal strength, appreciation of life, improved relationships, spiritual change, new life opportunities or positive behaviour changes (Aspinwall and Tedeschi, 2010). Posttraumatic growth has been studied in cancer, HIV/AIDS, cardiac disease, multiple sclerosis and rheumatoid arthritis and is consistently associated with quality of social support, coping strategies and various indicators of mental and physical health (Barskova and Oesterreich, 2009).

As well as defining and understanding what is meant by 'wellbeing', research has been conducted into how to improve it.

\section{Interventions to improving wellbeing}

Much of this work has been led by those involved in the 'positive psychology' movement. This was developed by American psychologist Martin Seligman to counter the perceived exclusive focus of psychological research into psychological dysfunction, and to consider what makes life worth living (Seligman \& Csikszentmihalyi, 2000). With this in mind, positive psychology interventions have been defined as those "aimed at raising positive feelings, positive cognitions or positive behaviour as opposed to interventions aiming to reduce symptoms, problems or disorders” (Bolier et al, 2013). For instance, interventions may aim to increase gratitude, enhance awareness of positive aspects of life or identify and make better use of personal strengths or talents. Box 1 details some example positive psychology interventions.

Box 1 - example interventions:

Box 1: Example interventions
The Three Good Things intervention
Participants are given the following instructions:
"Every night for the next week, before you go to sleep, write down three things that
went well today, and why they went well.”
Highest Strengths intervention
Participants are asked to complete the VIA Signature Strengths Questionnaire
(www.authentichappiness .org) to identify their five key strengths. Once they have identified
these they are asked: "Think of something that you have to do at school or at work every
week that you don't like doing. Given that you have found your signature strengths, think of
a way of doing that task using your highest strength."
Gratitude Journal
Participants are asked to keep a weekly gratitude journal. In this journal, the participant
writes down up to five things they were grateful for.
Research has demonstrated that these simple interventions have a significant effect on
improving mental health and wellbeing (Bolier et al, 2013)

A review of positive psychology interventions aimed at the general public and at people with specific psychosocial problems identified 39 studies, $n=6,139$ (Bolier et al, 2013). Overall, positive psychology interventions were found to be effective for improving wellbeing (standardized mean difference $=0.34$ ) and for reducing depressive symptoms (standardized 
mean difference $=0.23$ ). There remain a number of questions however, including which type of intervention is most effective in which people? Personality, culture, age, gender, social support, for example, may mediate intervention effectiveness (Rasmussen et al, 2009). What is the necessary intensity of interventions for effectiveness, including how often interventions should be delivered and over what period of time? And are there any detrimental effects of positive psychology interventions, and, if so, under what conditions may they occur?

The positive psychology approach to improving wellbeing therefore involves actively trying to improve life, and is rooted in nurturing existing strengths and resilience, rather than trying to correct deficits. Similarly, mindfulness approaches seek to start with the person where they are, b developing a particular type of awareness Mindfulness interventions have a foundation in Buddhism but are secular. The approach is one of learning to experience being present with awareness, acceptance and attention (White, 2013). Rather than trying to change uncomfortable thoughts or feelings, the individual practices to accepting these, without judgement. The original, standardised mindfulness intervention, mindfulness based stress reduction (MBSR) was developed by at the University of Massachutes Medical School by Dr. Jon Kabat-Zinn in 1979. Zinn originally developed the programme for people with chronic and/or life threatening medical conditions for whom standard medical treatment had been ineffective. The aim was to support patients in developing a way of being with their situation that enabled them to improve their current quality of life, regardless of their likely long term health outcome. The intervention is delivered over eight weeks ( 2 and a half hours per week) and includes psychoeducation, yoga and daily meditation practice to develop greater awareness of the mind and body. It also trains participants to learn about the ways they may be inadvertently undermining their own wellbeing by certain habitual ways of thinking, feeling, and behaving.

Systematic review evidence supports the effectiveness of MBSR in a range of clinical populations, including cancer, pain, heart disease, depression and anxiety as well as nonclinical populations(Grossman et al, 2004). Sixty-four studies were identified, 20 of which were considered to be of acceptable quality; these consistently produced effect sizes of around $0.5(P<.0001)$. A recent systematic review and meta-analysis analysed existing systematic reviews of standardized mindfulness programmes in healthcare (Gotink et al 2015). This included 115 RCTs and demonstrated significant improvements in depression, anxiety, quality of life, and physical functioning. More specifically, the practice of mindfulness has been found to be associated with physiological changes that can contribute to overall wellbeing. These include changes in grey matter concentration in brain regions that regulate emotion, learning, and memory (Hölzel et al, 2011), and also improved immune functioning (Carlson et al, 2013, Hoffman et al, 2012, Lengacher et al, 2012). MBSR has also been found to help nurses to manage stress and to improve their wellbeing and quality of life (Shapiro et al, 2005; Irving et al, 2009; Cohen-Katz et al, 2005); this is important since poor health and wellbeing in healthcare professionals is associated with reduced service quality and worse patient experience (Boorman, 2009; Maben et al, 2012). How nurses can improve their own wellbeing is discussed further in Barley (2016).

The popularity of mindfulness in the West has grown rapidly in the recent past. Therefore it is important that when suggesting to patients that they explore mindfulness that they are signposted to high quality interventions. A number of National Health Services in both primary and secondary care offer the standardised MBSR and the related Mindfulness Based Cognitive Therapy (for recurrent, chronic depression), which will be delivered by teachers who have a recognised level of proficiency to teach mindfulness. More information about 
mindfulness can be found on the Centre for Mindfulness Research and Practice Centre at Bangor University www.bangor.ac.uk/mindfulness

\section{Conclusion}

Wellbeing is a multidimensional construct which is associated with health outcomes and with functioning. There are a number of evidence-based interventions that can improve wellbeing. Nurses can draw on a range of wellbeing interventions and simple evidence based advice and guidance to help improve their patients' wellbeing when providing holistic care. Attention to their own wellbeing using the same techniques can also help nurses to deliver optimal care, whilst improving their own quality of life.

\section{References}

Aked J, Marks N, Cordon C, Thompson S (2008) Five Ways to Wellbeing: The Evidence. London: New Economics Foundation.

http://www.neweconomics.org/publications/entry/five-ways-to-well-being-the-evidence.

Antonovsky A (1987) Unraveling the Mystery of Health: How People Manage Stress and Stay Well. San Francisco.

Aspinwall LG \& Tedeschi RG (2010) The value of positive psychology for health psychology: progress and pitfalls in examining the relation of positive phenomena to health. Ann Behav Med. 2010, 39(1):4-15.

Barley, E. (2016) Health Psychology in Nursing Practice. London: Sage.

Barskova T, and Oesterreich R (2009) Post-traumatic growth in people living with a serious medical condition and its relations to physical and mental health: a systematic review. Disabil Rehabil.; 31(21):1709-33.

Bolier L, Haverman M, Westerhof GJ, Riper H, Smit F, Bohlmeijer E (2013) Positive psychology interventions: a meta-analysis of randomized controlled studies. BMC BMC Public Health. 13:119

Boorman S (2009) NHS Health and Wellbeing Review: Department of Health.

Carlson LE, Doll R, Stephen J, Faris P, Tamagawa R, Drysdale E, et al (2013) Randomized controlled trial of Mindfulness-based cancer recovery versus supportive expressive group therapy for distressed survivors of breast cancer. Journal of Clinical Oncology; 31(25):311926.

Cohen-Katz J, Wiley SD, Capuano T, Baker DM, Kimmel S, Shapiro S (2005) The effects of mindfulness-based stress reduction on nurse stress and burnout, Part II: A quantitative and qualitative study. Holist Nurs Pract. Jan-Feb;19(1):26-35.

Diener, E, \& Suh, E. (1997). Measuring quality of life: Economic, social, and subjective indicators. Social Indicators Research, 40 (1-2), 189-216. 
Dodge, R, Daly, A, Huyton, J, \& Sanders, L (2012). The challenge of defining wellbeing. International Journal of Wellbeing, 2(3), 222-235.

Eriksson M,Lindstrom B (2006) Antonovsky's sense of coherence scale and the relation with health: a systematic review. Journal of Epidemiology \& Community Health. 60(5):376-81.

Gotink R A, Chu P, Busschbach, J J, Benson H, Fricchione G L, \& Hunink, M M (2015) Standardised mindfulness-based interventions in healthcare: an overview of systematic reviews and meta-analyses of RCTs. PLoS One, 10(4), e0124344.

Grossman P, Niemann L, Schmidt S, Walach H (2004) Mindfulness-based stress reduction and health benefits. A meta-analysis. J Psychosom Res.;57(1):35-43.

Helgeson VS, Reynolds KA, Tomich PL (2006) A meta-analytic review of benefit finding and growth. Journal of consulting and Clinical Psychology. 74(5):797-816.

Henderson, L W, \& Knight, T (2012) Integrating the hedonic and eudaimonic perspectives to more comprehensively understand wellbeing and pathways to wellbeing. International Journal of Wellbeing, 2(3), 196-221.

Herzberg P Y, Glaesmer, H, \& Hoyer, J (2006) Separating optimism and pessimism: a robust psychometric analysis of the revised Life Orientation Test (LOT-R). Psychological assessment, 18(4), 433.

Hölzel BK, Carmody J, Vangel M, Congleton C, Yerramsetti SM, Gard T, et al (2011) Mindfulness practice leads to increases in regional brain gray matter density. Journal of Psychiatry Research: Neuroimaging;191(1):36-43.

Hoffman CJ, Ersser SJ, Hopkinson JB, Nicholls PG, Harrington JE, Thomas PW (2012) Effectiveness of mindfulness-based stress reduction in mood, breast- and endocrine-related quality of life, and well-being in stage 0 to III breast cancer: a randomized, controlled trial. Journal of Clinical Oncolog;30(12):1335-42.

Irving JA, Dobkin PL, Park J (2009) Cultivating mindfulness in health care professionals: a review of empirical studies of mindfulness-based stress reduction (MBSR). Complement Ther Clin Pract.15(2):61-6.

Kubzansky L D, Kubzansky P E, \& Maselko J (2004). Optimism and pessimism in the context of health: bipolar opposites or separate constructs? Personality and Social Psychology Bulletin, 30(8), 943-956.

Lengacher CA, Kip KE, Barta M, Post-White J, Jacobsen PB, Groer M, et al 2012 A pilot study evaluating the effect of mindfulness-based stress reduction on psychological status, physical status, salivary cortisol, and interleukin- 6 among advanced-stage cancer patients and their caregivers. Journal of Holistic Nursing;30(3):170-85. 
Maben J, Peccei R, Adams M, Robert G, Richardson A, Murrelss T and Morrow E (2012)

Patients' experiences of care and the influence of staff motivation, affect and wellbeing. Final report. NIHR Service Delivery and Organisation programme.

Merkes M(2010) Mindfulness-based stress reduction for people with chronic diseases. Aust J Prim Health;16(3):200-10.

Rasmussen HN, Scheier MF, Greenhouse JB (2009) Optimism and physical health: A metaanalytic review. Ann Behav Med; 37(3): 239-256.

Rohani C, Khanjari S, Abedi HA, Oskouie F, Langius-Eklof A (2010). Health index, sense of coherence scale, brief religious coping scale and spiritual perspective scale: psychometric properties. Journal of Advanced Nursing. 66(12):2796-806.

Seligman MEP, Csikszentmihalyi M (2002) Positive psychology. An introduction. American Psychologist. 55(1):5-14.

Sharpe JP, Martin NR, Roth KA. (2011) Optimism and the Big Five factors of personality: Beyond Neuroticism and Extraversion Personality and Individual Differences 51(8) 946-951. Shapiro SL, Astin JA, Bishop SR, Matthew C (2005) Mindfulness-Based Stress Reduction for Health Care Professionals: Results From a Randomized Trial. International Journal of Stress Management, 12(2), 164-176

Smith A, Fortune Z, Phillips R, Walters P, Lee GA, Mann A, Tylee A, Barley EA (2014) UPBEAT study patients' perceptions of the effect of coronary heart disease on their lives: a cross-sectional sub-study. International Journal of Nursing Studies. 51(11):1500-6.

Steptoe A, Deaton A, Stone AA.( 2015) Subjective wellbeing, health, and ageing. Lancet; 385: $640-48$

Warner L, Schwarzer, Schüz B, Wurm S, Tesch-Römer C (2012) Health-specific optimism mediates between objective and perceived physical functioning in older adults. J Behav Med. 35(4):400-6.

White L (2014) Mindfulness in nursing: an evolutionary concept analysis. J Adv Nurs. 70(2):282-94. 